ISSN 0103-9954

\title{
DETERMINAÇ̃̃O DA ÉPOCA DE DESBASTE PELA ANÁLISE DENDROCRONOLÓGICA E MORFOMÉTRICA DE Ocotea porosa (Nees \& Mart.) Barroso EM POVOAMENTO NÃO MANEJADO
}

\author{
DETERMINATION OF THE THINNING PERIOD BY DENDROCHRONOLOGICAL AND \\ MORPHOMETRIC ANALYSIS IN UNMANAGED STAND OF Ocotea porosa
}

\author{
Andreia Taborda dos Santos ${ }^{1}$ Patricia Póvoa de Mattos ${ }^{2}$ Evaldo Muñoz Braz ${ }^{3}$ Nelson Carlos Rosot ${ }^{4}$
}

\begin{abstract}
RESUMO
Plantios comerciais de Ocotea porosa disponíveis para estudo são raros e por esse motivo devem ser usados como fonte de informação para se estabelecer o potencial de manejo da espécie. A recuperação do histórico do crescimento desses povoamentos para estruturação dos planos de manejo é possível com o uso da técnica da dendrocronologia e a análise de dados dendrométricos e morfométricos. O objetivo desse trabalho foi utilizar ferramentas de análise de povoamentos florestais aliadas aos estudos dendrocronológicos, para recuperar e sistematizar o desenvolvimento de povoamento não manejado. $\mathrm{O}$ trabalho foi conduzido em um povoamento não manejado de imbuia, com 44 anos, em Rio Negro - PR, na Estação Experimental da UFPR. Inferências do crescimento recuperado por dendrocronologia, e competição pela aplicação de metodologias como índice de abrangência e de projeção de copa mostraram resultados compatíveis na análise do povoamento, indicando necessidade de primeiro desbaste próximo aos 12 anos. Em função do pequeno número de árvores amostradas, os resultados não permitem generalizações definitivas, entretanto, são consistentes para estabelecer um protocolo para análise de povoamentos não manejados de Ocotea porosa, assim como de outras espécies.
\end{abstract}

Palavras-chave: manejo florestal; competição; anéis de crescimento.

\begin{abstract}
Commercial plantations of Ocotea porosa available for studying are scarce and therefore should be used as a source of information to establish the potential for management of the species in plantations, even if these evaluations were not been held along the stand development. The recovery of the historical growth of these stands to optimize the management plans is possible by dendrochronology and by the analysis of morphometric and dendrometric data. The aim of this study was to use stand analysis tools, combined with the dendrochronological studies, to recover and to systematize the development of unmanaged stands. The study was conducted in an unmanaged stand of Ocotea porosa, with with 44 years of age in Rio Negro, PR state, in a UFPR research station. Growth inferences recovered by dendrochronology and the competition by the application of methodologies such as rate of coverage and crown cover rate showed consistent results in the analysis of population, indicating the need for a first thinning near 12 years old. Due to the small number of sampled trees, the results do not allow any definitive generalization. However, they are consistent to establish an
\end{abstract}

1 Engenheira Florestal, MSc., Professora na UNIBRASIL - Faculdades Integradas do Brasil, Rua Konrad Adenauer, 442, CEP 82821-020, Curitiba (PR), Brasil. andreiataborda@yahoo.com.br

2 Engenheira Agrônoma, rra $^{\mathrm{a}}$., Pesquisadora da Embrapa Florestas, Estrada da Ribeira, Km 111, Caixa Postal 319, CEP 83411-000, Colombo (PR), Brasil. patricia.mattos@embrapa.br

3 Engenheiro Florestal, Dr., Pesquisador da Embrapa Florestas, Estrada da Ribeira, Km 111, Caixa Postal 319, CEP 83411-000, Colombo (PR), Brasil. evaldo.braz@embrapa.br

4 Engenheiro Florestal, Dr., Professor do Departamento de Engenharia Florestal, Centro de Ciências Agrárias, Universidade Federal do Paraná, Av. Pref. Lothário Meissner, 900, CEP 80210-170, Curitiba (PR), Brasil. ncrosot@ufpr.br

Recebido para publicação em 28/06/2012 e aceito em 18/10/2013

Ci. Fl., v. 25, n. 3, jul.-set., 2015 
analysis protocol for unmanaged stands of Ocotea porosa or other species.

Keywords: forest management; competition; growth rings.

\section{INTRODUÇÃO}

A imbuia (Ocotea porosa) desempenhou um papel fundamental no desenvolvimento econômico e cultural na região sul do Brasil. Apesar da existência de instrumentos legais que impedem a exploração dessa espécie, sua madeira até hoje é considerada valiosa para a indústria de móveis e construção civil, em função de sua aparência, de seu lenho moderadamente pesado e resistente ao ataque de fungos (AMATO, 2008).

Alguns levantamentos florísticos mostram Ocotea porosa ocorrendo como abundante em remanescentes da Floresta Ombrófila Mista (LONGHI, 1980; NEGRELLE e SILVA, 1992; CALDATO et al., 1999; SCHAAF et al., 2006; HERRERA et al., 2009; ALBUQUERQUE et al., 2011). No entanto, sítios em que a espécie ocorre com baixa frequência, como em Turvo PR (ZAMPIERI e SALVADOR, 2006), aliados à intensa fragmentação da FOM (SANTOS et al., 2006; CAMPANILI e PROCHOW, 2006), levaram à inclusão de Ocotea porosa na lista oficial das espécies vulneráveis (MMA, 1992; IUCN, 2011), sendo incluída também na lista de espécies da flora brasileira ameaçada de extinção (BRASIL, 2006; 2008), inviabilizando o manejo dessa espécie em condições naturais (CAPOBIANCO, 2001; SANTOS et al., 2006), o que justifica os esforços para suprir a demanda de mercado com plantios comerciais de Ocotea porosa. De maneira geral, um grande esforço tem sido dedicado pelo governo à conservação dos remanescentes florestais, basicamente em duas frentes de ação, como a criação de Unidades de Conservação (UC) e a promoção do plantio de espécies florestais nativas.

Os programas governamentais de plantio de espécies nativas constituem uma medida para restaurar e proteger os remanescentes florestais. $\mathrm{O}$ plantio puro ou misto torna-se uma alternativa viável com potencial mais imediato para a conservação desses recursos naturais tão importantes, sendo uma alternativa para uma maior disponibilidade de madeira, bem como a manutenção das espécies nativas. No entanto, pouco tem sido desenvolvido ou pesquisado nesta área com relação ao binômio crescimento/manejo.
Estimativas seguras da capacidade produtiva de um plantio florestal podem ser obtidas com avaliação precisa do crescimento. Para o desenvolvimento de planos de manejo, faz-se necessário averiguar o potencial produtivo de cada povoamento em diferentes sítios, de maneira que o crescimento e a produção possam ser prognosticados (ALEMDAG, 1991). Uma decisão correta sobre a época de corte de cada povoamento, espécie ou, de cada talhão, exige o conhecimento da taxa de crescimento e a produção por unidade de área, segundo a idade, a capacidade produtiva e a densidade (ROSAS, 1994). A idade se constitui na primeira variável independente considerada nos estudos de crescimento e produção de povoamentos equiâneos, e traduz o tempo físico decorrido desde a implantação da floresta até o momento da avaliação (RODRIGUEZ, 1991).

Plantios comerciais ou experimentais de imbuia são raros, e devem ser considerados como preciosos registros de crescimento, podendo ser usados como fonte de informação para se estabelecer o potencial de manejo da espécie sob condições de plantio, mesmo que essas informações e avaliações não tenham sido realizadas ao longo do período de desenvolvimento do povoamento. A recuperação do histórico do crescimento desses povoamentos para otimização dos planos de manejo é possível pela dendrocronologia (SPIECKER, 2002; MATTOS et al., 2011). A imbuia é uma espécie que apresenta anéis de crescimento distintos (RONDON NETO, 2003; TOMAZELLO FILHO et al., 2004; LISI et al., 2008), já existindo em literatura exemplos de trabalhos com resultados da aplicação dessa ferramenta na compreensão do ritmo de crescimento dessa espécie (RONDON NETO, 2003, MATTOS et al., 2007, 2010).

Além disso, outra análise importante se refere às características morfométricas. Estudos do crescimento de árvores baseados em suas características singulares (dimensões, relações morfométricas) e em razão de fatores ambientais, têm sido muito enfocados nos últimos anos (VANCLAY, 1994; ROMAN et al., 2009; DURLO e DENARDI, 1998), em consequência das interpretações e inferências silviculturais que permitem e pela possibilidade de seu uso para 
modelagem do crescimento florestal.

O objetivo desse trabalho foi utilizar ferramentas de análise de povoamentos florestais aliadas aos estudos dendrocronológicos, para recuperar e sistematizar o desenvolvimento de povoamento não manejado, como embasamento para a determinação de critérios para o planejamento do manejo de novos reflorestamentos com Ocotea porosa.

\section{MATERIAIS E MÉTODOS}

A coleta de dados foi realizada na Estação Experimental de Rio Negro, administrada pelo Curso de Engenharia Florestal da Universidade Federal do Paraná e localizada às margens da rodovia BR-116 ( $\mathrm{km} \mathrm{200),} \mathrm{distrito} \mathrm{de} \mathrm{Tijuco} \mathrm{Preto,}$ distante cerca de $110 \mathrm{~km}$ do centro de Curitiba com coordenadas $26^{\circ} 04^{\prime} 02,40^{\prime \prime} \mathrm{S}$ e $49^{\circ} 45^{\prime} 58,76^{\prime \prime} \mathrm{W}$.

O clima da região, segundo a classificação climática de Köppen, é do tipo $\mathrm{Cfb}$, clima mesotérmico com temperatura média do mês mais frio inferior a $18^{\circ} \mathrm{C}$ e superior a $-3^{\circ} \mathrm{C}$, com pelo menos um mês com média igual ou superior a $10^{\circ} \mathrm{C}$. O clima é sempre úmido, com o mês mais seco apresentando precipitações superiores a $60 \mathrm{~mm}$, com verões brandos e temperatura média no mês mais quente inferior a $22^{\circ} \mathrm{C}$ (LONGHI, 1980).

Os dados utilizados para desenvolver este trabalho foram obtidos em experimento implantado em 1967, em 32 parcelas com espaçamento de 1,9m x 3,0m totalizando 0,89 ha. Foi realizada a medição dos diâmetros a 1,30 m do solo (DAP) de todas as árvores do povoamento.

As árvores foram selecionadas aleatoriamente, de acordo com a qualidade do fuste e distribuídas em 7 classes diamétricas, definidas em função da média e desvio padrão dos diâmetros das árvores do povoamento, conforme descrito em Santos et al. (2012). Foram derrubadas duas árvores por classe diamétrica, totalizando 12 árvores. Foram medidas as alturas totais das 12 árvores e a altura do povoamento foi estimada por relação hipsométrica, que serviu para cálculo do índice de abrangência.

\section{Ajuste de equação de crescimento}

De cada árvore-amostra foi retirado um disco a 1,30 $\mathrm{m}$ de altura (diâmetro a altura do peito - DAP) e outro da base. Os discos foram secos à temperatura ambiente e posteriormente lixados para melhor visualização dos anéis de crescimento, sendo utilizadas lixas com granulometria variando de 40 até 400 .

Os anéis de crescimento foram contados e medidos em oito raios para as amostras retiradas a 1,30 m de altura do solo, para maior precisão da estimativa do incremento médio e corrente anual (IMAdap e ICAdap) em diâmetro e em quatro raios para as amostras retiradas da base, para datação dos anéis de crescimento entre discos da mesma árvore e para estimativa da idade de cada árvore. A medição foi feita com auxílio de microscópio estereoscópico e de mesa de mensuração de anéis, com precisão de $0,01 \mathrm{~mm}$.

Foi efetuada análise de variância para identificação de diferenças significativas entre os valores de IMAdap e ICAdap em função da classe diamétrica. A comparação das médias foi realizada pelo teste Tuckey a $5 \%$ de probabilidade de confiança. Na sequência, foram ajustadas equações de crescimento para cada classe de diâmetro considerada. As equações de crescimento testadas foram Schumacher, Logística, Chapmann Richards e Gompertz, e os critérios de seleção foram o coeficiente de determinação $\left(\mathrm{R}^{2}\right)$, o erro padrão da estimativa em porcentagem (Syx\%) e o teste F.

\section{Avaliação de índices morfométricos}

Para cada árvore selecionada para corte, denominada árvore principal, mediu-se o DAP com fita métrica e, após a derrubada, a altura total com trena. A distância entre as árvores concorrentes ou vizinhas em relação à principal foi medida com trena e a altura de cada dessas árvores foi estimada utilizando a altura da árvore principal como referencia.

Das árvores selecionadas para corte e de cada uma de suas concorrentes determinou-se o diâmetro de copa (dc), a partir da medição de oito raios de projeção de copa, com o auxílio de fita métrica, considerando cada raio como a distância do tronco até o ponto extremo da projeção da copa. O primeiro raio foi tomado partindo do ponto cardeal Norte, sendo os seguintes medidos na sequência: noroeste, oeste, sudoeste, sul, sudeste, leste e nordeste, determinados com o auxílio de bússola.

A partir dos dados de campo, foram calculadas as seguintes variáveis para cada árvore: a) Raio médio $(\mathrm{Rm})$ : calculado pela média aritmética dos oito raios de copa.

b) Diâmetro de copa (Dc): determinado por $2 x \mathrm{Rm}$.

c) Área de projeção da copa (Sc): calculada usando 
os raios médios de copa $\left(S c=I \pi c^{2}\right.$ em que: $\mathrm{Sc}=$ área de projeção da copa $\mathrm{em}^{2} ; \mathrm{Rc}=$ raio médio da copa em metros).

d) Número potencial de árvores por hectare para cada área de projeção de copa $(N p=10.000 / S c$, em que: $\mathrm{Np}=$ número potencial de árvores por hectare; $10.000=$ área em $\mathrm{m}^{2}$ equivalente a 1 hectare e $\mathrm{Sc}=$ área de projeção da copa em $\mathrm{m}^{2}$ ).

A competição foi avaliada por meio de índices de concorrência independentes e dependentes da distância, para cada árvore selecionada, sendo Basal Area Larger (BAL) e Glover e Hool, os índices independentes da distância e o índice de Hegyi o índice dependente da distância.

Os índices de saliência (IS) e de abrangência (IA). Esbeltez (GE) das árvores foram calculados usando planilha eletrônica, em que IS = DC/DAP e (GE) calculado por:

$\mathrm{Ge}=\mathrm{Dc} / \mathrm{h}$, sendo $\mathrm{Dc}=$ diâmetro de copa em metros e $\mathrm{h}=$ altura da árvore em metros.

As fórmulas utilizadas para cálculo dos índices de competição foram retiradas do trabalho de Kiernan et al. (2008), As quais seguem abaixo:

Basal Area Larger - BAL é calculado pela fórmula $B A L=i=1 n g$, sendo $n=$ número de árvores com circunferência a altura do peito maior que a árvore-amostra no ponto amostral; $\mathrm{g}=$ área transversal, em metros quadrados.

Índice de Glover e Hool, caluculado pela fórmula $\mathrm{IGH}=\mathrm{di} 2 \mathrm{~d} 2$, em que di = diâmetro da árvore considerada, em centímetros; $\mathrm{d}=$ diâmetro médio das seis árvores vizinhas da considerada, em centímetros e o índice de Hegyi calculado pela fórmula $\mathrm{IH}=\mathrm{i}=1$ ndidj1Lij, sendodi e $\mathrm{dj}=$ diâmetro da árvore considerada e concorrente, em centímetro, respectivamente; $1 \mathrm{ij}=$ distância até a concorrente $\mathrm{j}$, em metros.

\section{Determinação da densidade ótima de árvores por hectare}

Com a equação hipsométrica de Henricksen, conforme Santos et al. (2012), foi ajustada uma equação para obtenção das alturas por classe de diâmetro para cálculo do índice de abrangência. Assim, utilizando-se a área de projeção de copa, o índice de abrangência e altura dominante das árvores dominantes e codominantes, de acordo com metodologia utilizada por Schneider e Schneider (2008), foi determinado o número ideal de árvores de acordo com o diâmetro médio alcançado
(CLUTTER et al., 1983; ABETZ e OHNEMUS, 1994).

\section{Projeção de copa}

A área da projeção de copa é calculada pela fórmula $P C=\pi d^{2} / 4$, sendo $\mathrm{d}=$ diâmetro médio de copa de 4 medições de diâmetros em metros.

Assim, $N=10.000 / P c$, sendo $\mathrm{N}=$ Número de árvores; $10.000=$ área $\mathrm{em} \mathrm{m}^{2}$ equivalente a um hectare e $\mathrm{Pc}=$ projeção de copa $\mathrm{em}^{2}$ do diâmetro médio do povoamento.

\section{Índice de abrangência, altura dominante e espaço vital}

Para calcular o espaço vital da árvore utilizou-se a equação $\mathrm{ev}=I \mathrm{~A} x \mathrm{hdom}$, sendo $\mathrm{ev}=$ espaço vital da árvore; IA = índice de abrangência e hdom $=$ altura dominante.

Assim, para obter a densidade ótima de árvores por hectare no povoamento, efetuou-se o cálculo $N=10.000 / e v^{2}$, sendo $\mathrm{N}=$ número de árvores com possibilidade de serem estocadas em diâmetro médio especificado; 10.000 = área equivalente a 1 hectare $\mathrm{em} \mathrm{m}^{2} \mathrm{e} \mathrm{ev}^{2}=$ espaço vital da árvore $\mathrm{em} \mathrm{m}^{2}$.

\section{RESULTADOS E DISCUSSÃO}

Os discos da base, das árvores maiores apresentaram 44 camadas de crescimento, confirmando a idade de implantação do povoamento. Alguns autores como Poussart et al. (2004), Chowdhury et al. (2008), Nicolini et al. (2010) indicaram a confirmação da idade em árvores plantadas pela contagem das camadas de crescimento.

As árvores com menores diâmetros apresentaram menor número de anéis de crescimento na base, algumas chegando a ter 29 camadas a menos que a idade esperada, refletindo a condição de crescimento insatisfatório, em árvores suprimidas com estagnação completa. Anéis de crescimento ausentes são frequentes em árvores suprimidas, em condições naturais ou em plantios como relatado por Lorimer et al. (1999) para Acer saccharum.

$\mathrm{O}$ incremento médio anual em diâmetro das árvores estudadas foi igual a $0,61 \mathrm{~cm} \mathrm{ano}^{-1}$, variando de $0,03 \mathrm{~cm}^{2} o^{-1}$ a $1,53 \mathrm{~cm}^{2}$ ano ${ }^{-1}$. 
As árvores que atingiram as posições superiores no dossel apresentaram os maiores diâmetros e maiores taxas de incremento, no período analisado, este padrão de crescimento, já relatado por Assmann (1970) e Silva et al. (2003) em árvores da Bacia do rio Cuieiras, na Amazônia Central. Isso pode ocorrer devido à maior atividade fotossintética, uma vez que essas árvores, de acordo com Hubbell et al. (1999), em sua grande maioria, ocupam o dossel superior da floresta tendo principalmente maior oferta de luz.

No Sudeste Asiático, na Malásia Peninsular, Manokaran e Kochummen (1993) apresentaram os resultados de incremento para 48 espécies florestais, sendo que as espécies do dossel cresceram entre 0,5 a 3,5 $\mathrm{mm}$ ano $^{-1}$. Na América Tropical, Clark e Clark (1987), na estação La Selva na Costa Rica, para a espécie Dipteryx panamensis encontraram um incremento médio de 5 a $8 \mathrm{~mm}$ ano $^{-1}$.

Embora seja esperado um maior crescimento em plantio do que em florestas nativas, o crescimento médio observado neste estudo foi semelhante ao relatados por Figueiredo-Filho (2003); Schaaf et al. (2005); Sanquetta et al. (2007); Mattos et al. (2007) para de indivíduos de Ocotea porosa em condições naturais nos estados do Paraná e Santa Catarina, uma vez que se trata de um povoamento sem tratamentos silviculturais.

Sanquetta et al. (2007) observaram incrementos de $0,14 \mathrm{~cm}^{2} \mathrm{ano}^{-1}$ a $0,20 \mathrm{~cm}^{\mathrm{ano}}{ }^{-1}$, semelhante aos observados para árvores dominadas e suprimidas no plantio aqui estudado. Figueiredo Filho (2003) em Irati - PR; Schaaf et al. (2005) em São João do Triunfo - PR e Mattos et al. (2007) observaram incrementos médios anuais variando entre $0,25 \mathrm{~cm}^{2} o^{-1}$ a $0,35 \mathrm{~cm}^{2} o^{-1}$ compatível com os valores encontrados para as árvores codominantes.

Finalmente, árvores com incremento periódico anual aos 20 anos de $0,57 \mathrm{~cm}^{\text {ano }}{ }^{-1}$ foram observadas por Mattos et al. (2010), em FOM em Caçador - SC, valor semelhante ao observado para as árvores dominantes neste estudo.

Essas diferenças observadas em condições naturais podem ser decorrentes da variabilidade genética, das características ambientais do local, ou mesmo das condições de competição presentes e passadas. Por esse motivo, para implantação de novos povoamentos, deve-se ter o cuidado de se identificar em campo as progênies que apresentem melhor desempenho em ambientes semelhantes aos do plantio, para a composição do material genético que irá formar esse novo povoamento. Alguns trabalhos como os de Kalil Filho et al. (2004, 2008) mostram a importância de se estudar a variabilidade genética de Ocotea porosa. No entanto, muitas vezes são desconsideradas na fase de planejamento e implantação de novas áreas, pois informações sobre o crescimento de espécies nativas nem sempre são publicadas de forma sistematizada.

Pela grande diferença diamétrica entre árvores, optou-se por proceder à análise de crescimento considerando quatro categorias sucessionais, conforme apresentado na (Tabela 1). Para cada um dos quatro grupos, foi ajustada uma equação de crescimento em diâmetro (Figura 1). Para as classes que obtiveram menor diâmetro (dominadas e suprimidas), o melhor ajuste foi obtido com a equação de Chapman-Richards e para as classes dominantes e codominantes, a equação de Gompertz ajustou-se melhor. Observou-se um ajuste das equações obtidas (Tabela 1), com alto $\mathrm{R}^{2}$, baixo

TABELA 1: Diâmetro médio, coeficientes e estimadores de ajuste e precisão dos melhores modelos de crescimento para Ocotea porosa com 44 anos de plantio.

TABLE 1: Average diameter, coefficients and estimator adjusts and precision of the best growth models for Ocotea porosa, with 44 years old.

\begin{tabular}{cccccccc}
\hline \multirow{2}{*}{ Classe } & \multirow{2}{*}{ DAP $(\mathrm{cm})$} & \multicolumn{3}{c}{ Coeficientes } & \multicolumn{3}{c}{ Ajuste } \\
\cline { 3 - 8 } & & $\mathrm{b}_{0}$ & $\mathrm{~b}_{1}$ & $\mathrm{~b}_{2}$ & $\mathrm{R}^{2}$ & Syx $\%$ & $\mathrm{~F}$ \\
\hline Dominante $(\mathrm{G})$ & 6,5 & 39,0801 & 1,2603 & 0,0770 & 0,994644 & 12,12408 & $3.796,93^{*}$ \\
Codominante (G) & 18,3 & 27,8056 & 1,1607 & 0,0858 & 0,995426 & 11,0289 & $4.053,04^{*}$ \\
Dominada (C-R) & 27,6 & 1,0 & $-0,6734831$ & $-0,9391622$ & 0,921403 & 20,12728 & $283,93^{*}$ \\
Suprimida (C-R) & 39,3 & 8,1390 & 1,0297 & 0,0586 & 0,803757 & 36,9465 & $51,0^{*}$ \\
\hline
\end{tabular}

Em que: DAP = diâmetro médio da classe considerada; $\mathrm{G}$ = equação de Gompertz; C-R = equação de ChapmanRichards; b0, b1, b2 = coeficientes da equação; $\mathrm{R}^{2}$ = coeficiente de determinação; Syx\% = erro padrão da estimativa e $\mathrm{F}=$ valor de $\mathrm{F}$ da análise de variância, $*=95 \%$ de probabilidade de confiança. 
Syx $\%$ e alto valor de $\mathrm{F}$, com melhor ajuste para as classes com crescimento maior (codominantes e dominantes).

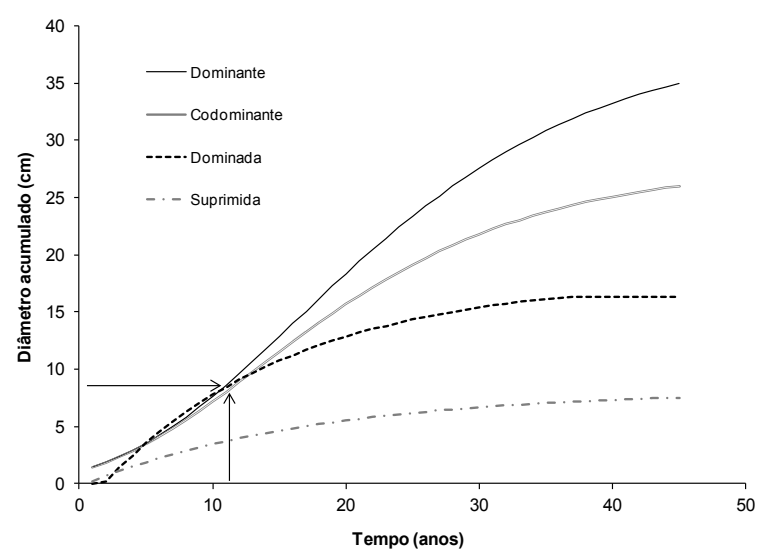

FIGURA 1: Curvas de crescimento em diâmetro para Ocotea porosa em plantio homogêneo aos 44 anos de idade para quatro classes sociológicas.

FIGURE 1: Growth diameter curves for Ocotea porosa in homogeneous forest plantation of 44 years old, for four sociological classes.

Como esperado, a taxa de crescimento foi maior em posições de plena luz solar, decrescendo à medida que diminuiu o grau de exposição da copa à luz. Na Figura 1 é possível visualizar as quatro classes de crescimento em diâmetro, bem como o ponto de inversão da curva para cada classe (ponto de encontro das setas de identificação), ou redução do crescimento, sendo que, para a classe suprimida, a redução do crescimento ocorre a partir do quarto ano e para as classes dominadas, codominantes e dominantes essa redução ocorre por volta dos 12 anos no DAP. Neste ponto pode-se inferir o momento em que a competição por luz começou a interferir no crescimento das árvores.

A partir desse resultado, os dados de incremento anual (IMAdap) foram reorganizados por classe diamétrica e posição sociológica (tratamento), sendo observadas diferenças significativas entre as árvores estudadas. Observouse que as árvores dominantes apresentam redução do crescimento mais lenta do que nas demais classes (Tabela 2).

A Ocotea porosa é a espécie arbórea mais longeva da "mata de araucária" podendo ultrapassar os 500 anos de idade. Em Santa Catarina encontrouse um exemplar de mais de 2.700 anos (CARVALHO, 2003). Mattos et al. (2010), em trabalho realizado na Reserva Florestal Embrapa/Epagri, Caçador - SC, com medições dos anéis de crescimento, apresentaram resultados de crescimento em 90 anos, com maior crescimento para árvores de imbuia com diâmetros entre 80 a $100 \mathrm{~cm}$ de DAP. Entretanto, sob condições de plantio, podem ocorrer mudanças no ritmo de crescimento da árvore, como relatado por Ricken et al. (2011) em Adrianópolis, para cedro australiano (Toona ciliata M. Roem. var. australis (F.v.M.) C.DC.) que apresentou um ciclo econômico sob plantio naquelas condições de não mais que 12 anos e diâmetro de $80 \mathrm{~cm}$, confrontando com relatos de literatura sob condições naturais, em que a espécie é apresentada como longeva, com potencial para atingir até $3 \mathrm{~m}$ de diâmetro (BOLAND et al.,

TABELA 2: Incremento médio anual para árvores de imbuía por classe diamétrica e posição sociológica em plantio homogêneo na estação experimental de Rio Negro - PR.

TABLE 2: Mean annual increment of Ocotea porosa trees by diametric classes and sociological position in homogeneous stand in Rio Negro experimental station.

\begin{tabular}{cccccc}
\hline Diâmetro & Todas as árvores & Dominante & Codominante & Dominadas & Suprimidas \\
\hline Até $5 \mathrm{~cm}$ & $0,50304 \mathrm{a}$ & $0,63013 \mathrm{c}$ & $0,68766 \mathrm{ab}$ & $0,50246 \mathrm{a}$ & $0.34837 \mathrm{a}$ \\
$5-10$ & $0,73432 \mathrm{a}$ & $1,01810 \mathrm{a}$ & $0,84587 \mathrm{a}$ & $0,67244 \mathrm{a}$ & $0.42478 \mathrm{a}$ \\
$10-15$ & $0,66216 \mathrm{a}$ & $1,07048 \mathrm{a}$ & $0,75849 \mathrm{a}$ & $0,60998 \mathrm{a}$ & $0.17530 \mathrm{~b}$ \\
$15-20$ & $0,57218 \mathrm{a}$ & $1,06920 \mathrm{a}$ & $0,73836 \mathrm{a}$ & $0,15122 \mathrm{~b}$ & - \\
$20-25$ & $0,63939 \mathrm{a}$ & $0,96194 \mathrm{ab}$ & $0,45507 \mathrm{bc}$ & - & - \\
$25-30$ & $0,60192 \mathrm{a}$ & $0,71986 \mathrm{dc}$ & $0,26493 \mathrm{c}$ & - & - \\
$30-35$ & $0,52479 \mathrm{a}$ & $0,58310 \mathrm{c}$ & - & - & - \\
$35-40$ & $0,53625 \mathrm{a}$ & $0,53625 \mathrm{c}$ & - & - & - \\
\hline
\end{tabular}

Em que: Médias seguidas das mesmas letras nas colunas não diferem estatisticamente entre si pelo teste de Tukey. 
2006).

A floresta natural no Brasil ainda é carente em técnicas específicas para tratamentos silviculturais. Os resultados de maior crescimento observados com maior espaço vital podem ser relevantes para o manejo desta espécie também em condições naturais.

\section{Índices de competição e índices morfométricos}

O diâmetro a altura do peito e o diâmetro de copa (Figura 2) apresentaram correlação $r$ de $0,77$. Dessa forma, foi possível inferir a relação entre as dimensões obtidas pelo DAP ao longo do tempo e área de projeção de copa.

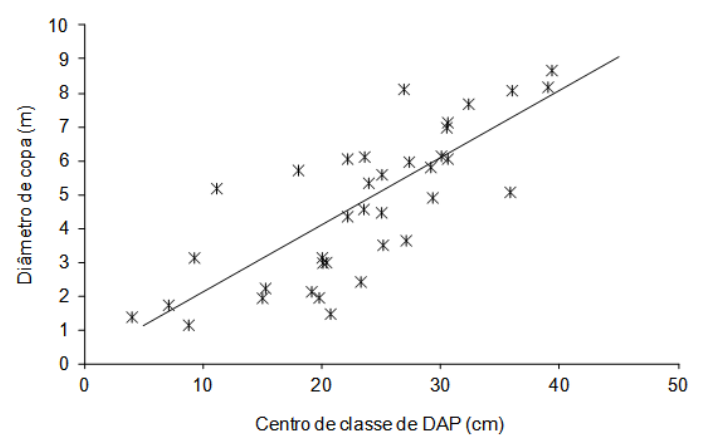

FIGURA 2: Diâmetro de copa em relação do diâmetro a altura do peito.

FIGURE 2: Crown diameter in relation to diameter at breast height.

O índice de saliência obtido no povoamento em estudo foi de 21, indicando que existe forte competição. Em estudos realizados por Tonini e Arco-Verde (2005), com castanheira-doBrasil (Bertholletia excelsa); andiroba (Carapa guianensis); ipê-roxo (Tabebuia avellanedae) e jatobá (Hymenaea courbaril) foram encontrados valores que variaram de 14,7 a 50,3, com indicação de alta competição a partir de 25. Catinot (1974) observou espécies de baixa produção volumétrica na África, com índice de saliência de 40.

A área da copa é calculada a partir do diâmetro de copa, para se verificar o grau de ocupação de cada árvore. Sabe-se que para uma determinada área de projeção de copa, o incremento é maior para árvores com melhor posição sociológica (ASSMANN, 1970).

O povoamento em estudo foi estabelecido com 1.754 indivíduos por hectare. A Tabela 3 mostra o ponto de transição inicial entre copas livres e copas em início de sobreposição e competição (com $13 \mathrm{~cm}$ de DAP) coincidindo com resultados observados na Figura 1; também mostra o número suportável de árvores de acordo com o diâmetro médio atingido pelo povoamento. A aplicação dos dois métodos para interpretação do espaço disponível para as árvores do povoamento, em função dos DAPs e do diâmetro médio das copas indica que até os 12 anos o espaço individual médio não apresenta comprometimento. No entanto, quando as árvores atingiram $13 \mathrm{~cm}$ de DAP médio há o indicativo de que estas precisariam de espaço individual maior, como indicado nas curvas de crescimento da Figura 1. Assim, pode-se definir o momento em que o povoamento começa a competir pelo espaço vital de cada árvore. Aplicando-se o método do Índice de abrangência e altura dominante a redução deveria ter sido no mínimo para 1.557 plantas por hectare, e segundo o método de projeção de copa para 1.717 árvores por hectare. Esta redução proporcionaria aumento do espaço vital para as árvores, possibilitando retomada do crescimento até quando as copas voltassem a competir, demandando novo desbaste. A ocupação do espaço individual máximo como critério para definição do momento ideal de desbaste está de acordo com Durlo (2001), que menciona que tão logo se feche o espaço aéreo pelas copas, começa a diferenciação de classes sociológicas em função da competição entre árvores, o que acarretaria maior comprometimento do crescimento daquelas que não ficarem na classe superior.

Na Figura 3 são apresentadas as estimativas do número ideal de árvores, em função do diâmetro médio do povoamento, pelo método de índice de abrangência e altura dominante e pelo de projeção de copa, com $\mathrm{R}^{2}$ superior a 0,96 . Observa-se que, apesar da semelhança entre as curvas, o índice de abrangência é um método um pouco mais rígido, reduzindo em 20,51\% o número de árvores com relação ao método de diâmetro de copa, em situação de DAP médio do povoamento de $40 \mathrm{~cm}$ (Tabela 3).

Segundo Assmann (1970), o espaçamento médio de crescimento das árvores de um povoamento é inversamente proporcional ao número de árvores e diretamente proporcional ao diâmetro médio. Assim, conclui, que quanto maior a área basal por hectare, menor o espaço médio de crescimento e menor o incremento. A importância das variáveis da copa para a modelagem do crescimento em diâmetro já foi confirmada por outros autores (Durlo e Denardi (1998) e Durlo (2001) para Cabralea canjerana (Well.) Mart.; Nutto (2001) para Araucaria 
TABELA 3: Ponto de equilíbrio de número de árvores por hectare, de acordo com o diâmetro médio do povoamento (DAP).

TABLE 3: Balanced number of trees per hectare according to the average diameter at breast height of the stand $(\mathrm{DBH})$.

\begin{tabular}{|c|c|c|c|c|}
\hline DAPs médios & Diâmetro copa (m) & Área copa & $\begin{array}{c}\text { n.árv.ha-1 }^{-1} \\
\text { (proj.de copa) }\end{array}$ & $\begin{array}{c}\text { n.árv.ha }^{-1} \\
\text { (Índice de abrangência e altura dom.) }\end{array}$ \\
\hline 10 & 2,1 & 3,55 & 2.813 & 2.700 \\
\hline 11 & 2,3 & 4,25 & 2.353 & 2.209 \\
\hline 12 & 2,5 & 5,01 & 1.998 & 1.840 \\
\hline 13 & 2,7 & 5,82 & 1.717 & 1.557 \\
\hline 14 & 2,9 & 6,70 & 1.492 & 1.334 \\
\hline 15 & 3,1 & 7,65 & 1.308 & 1.156 \\
\hline 20 & 4,1 & 13,28 & 753 & 638 \\
\hline 23 & 4,7 & 17,41 & 574 & 479 \\
\hline 25 & 5,1 & 20,47 & 489 & 404 \\
\hline 30 & 6,1 & 29,20 & 342 & 279 \\
\hline 35 & 7,1 & 39,48 & 253 & 204 \\
\hline 40 & 8,1 & 51,31 & 195 & 155 \\
\hline
\end{tabular}

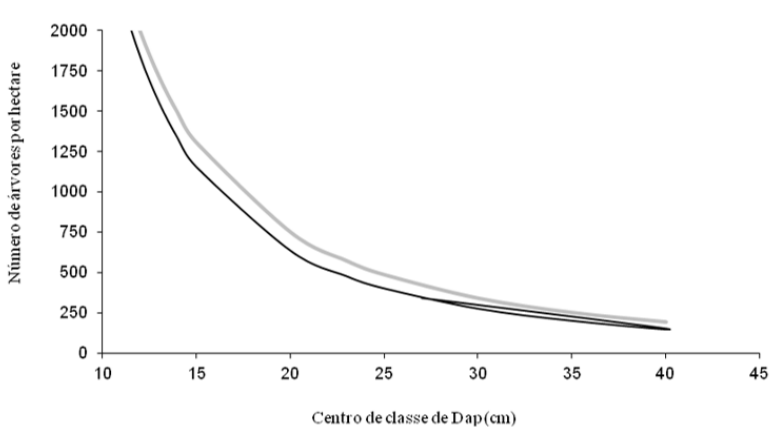

FIGURA 3: Número de árvores e diâmetro médio atingido.

FIGURE 3: Number of trees and average diameter achieved.

angustifólia (Bertol.) Kuntze; Tonini e Arco-Verde (2005) para Bertholletia excelsa Bonpl.; Carapa guianensis Aubl.; Tabebuia avellanedae Lorentz ex Griseb. e Hymenaea courbaril L.; Roman et al. (2009) para Cordia trichotoma (Vell.) Arráb. ex Steud, entre outros).

$\mathrm{O}$ efeito negativo da competição no crescimento das árvores é confirmado por vários estudos de crescimento em árvores (WYKOFF, 1990; HOLMES e REED, 1991; QUICKE et al., 1994; BIGING e DOBBERTIN, 1995; HASENAUER e MONSERUD, 1996; MONSERUD e STERBA, 1996; STERBA et al., 2002) em que o incremento diminui com o aumento da competição. Isso mostra que tratamentos silviculturais e desbastes de condução são essenciais para o manejo de povoamentos para obtenção de maior rendimento por hectare, priorizando árvores com maior diâmetro e favorecendo seu crescimento pelo manejo adequado, independentemente de se tratar de espécies nativas ou exóticas.

\section{CONCLUSÕES}

O povoamento apresentou número de indivíduos de pequeno diâmetro muito superior ao esperado, mostrando alto nível de competição entre as árvores. Dessa forma, há indicativos de necessidade de desbaste em função da distribuição diamétrica, da análise das curvas de crescimento em diâmetro por classe diamétrica, pelos índices de competição e pelos índices morfométricos.

Inferências do crescimento recuperado pelo estudo dos anéis de crescimento e competição pela aplicação de metodologias como índice de abrangência, projeção de copa e curvas de crescimento, mostraram resultados compatíveis na análise do povoamento, indicando idade próxima a 12 anos e DAP médio de $13 \mathrm{~cm}$, como a primeira indicação da necessidade de desbaste.

A Ocotea porosa apresenta crescimentos marcadamente diferenciados, de acordo com o nível de competição. Isso determinou o ajuste de curva 
de crescimento em diâmetro em função das classes sociológicas, com as árvores de maior diâmetro sendo representadas pela equação de Gompertz e as de menor diâmetro pela equação de ChapmanRichards.

Em função do pequeno número de árvores amostradas, os resultados não permitem generalizações definitivas, entretanto, são consistentes para estabelecer um protocolo para análise de povoamentos não manejados de Ocotea porosa, assim como de outras espécies.

\section{REFERÊNCIAS BIBLIOGRÁFICAS}

ABETZ, P.; OHNEMUS, K. Der Z-BaumBestockungsgrad (Definition, Herleitung, Anwendung). Allg. Forst- u. J.-Ztg., v. 165, n.10-12, p.177-185, 1994.

ALBUQUERQUE，J.M; WATZLAWICK， L.F.; MESQUITA, N. S. Efeitos do uso em sistema faxinal na florística e estruturas em duas áreas da Floresta Ombrófila Mista no município de Rebouças, PR. Ciência Florestal, Santa Maria, v. 21, n. 2, p. 323 - 334, abr - jun, 2011.

ALEMDAG, I. S. National site-index and heightgrowth curves for white spruce growing in natural stands in Canada. Canadian Journal of Forest Research, v. 21, p.1466-1474, 1991.

AMATO, C. M. Ecologia de populações de Ocotea Porosa (Nees) Barroso em áreas submetidas a diferentes graus de pertubação. Dissertação (Mestrado) - Universidade Federal do Paraná, Curitiba. 2008. $57 \mathrm{f}$.

ASSMANN, E. The principles of forest yield study: studies in the organic production, structure, increment and yield of forest stands. Oxford: Pergamon Press, 1970. 506 p.

BIGING, G. S.; DOBBERTIN, M. Evaluation of competition indices in individual tree growth models. Forest Science, v. 41, p. 360-377, 1995.

BOLAND, D. J. et al. Rosewood: rose mahogany. In: Forest trees of Australia. $5^{\text {th }}$. ed. Collingwood: CSIRO 2006. p.122-125.

BRASIL. Lei Federal No 8.171 - 17 de janeiro de 1991 - Dispõe sobre a política agrícola. Disponível em: https://www.planalto.gov.br/ccivil_03/leis/ 18171.htm Acesso em agosto de 2011.

BRASIL. Lei da Mata Atlântica (2006). In: Constituição da República Federativa do Brasil (1988), Coletânea de Legislação de Direito Ambiental. MEDAUAR, O. (org.). 5. ed. São Paulo: Revista dos Tribunais, 2006.
CALDATO, S. L.; LONGHI, S. J.; FLOSS, P. A. Estrutura populacional de Ocotea porosa (Lauraceae) em uma Floresta Ombrófila Mista, em Caçador (SC). Ciência Florestal, Santa Maria, v. 9, n. 1, p. 89-101, 1999.

CAMPANILI, M.; PROCHNOW, M. Mata Atlântica - Uma rede pela floresta. Brasília: RMA, 2006. 332 p.

CAMPOS, J. C. C.; LEITE, H. G. Mensuração Florestal: perguntas e respostas. Viçosa: UFV, 407 p., 2009.

CAPOBIANCO, J.P. R. Situação atual e perspectivas para a conservação da Mata Atlântica. In: LIMA, A. Aspectos jurídicos da proteção da Mata Atlântica. São Paulo: Instituto Socioambiental, 2001, p.9-15. (Documentos do ISA; 7).

CARVALHO, P. E. R. Espécies Arbóreas Brasileiras. Colombo: Embrapa Florestas, 2003.

CATINOT, R. LE presént et l'avenir des forêts tropicales humides. Revue Bois et forêts des tropiques, n. 154, p. , 1974.

CHOWDHURY, M. Q. et al. Nature and periodicity of growth rings in two Bangladeshi mangrove species. IAWA Journal, v. 29, p. 265-276, 2008.

CLARK, D. B.; CLARK, D. A. Population Ecology and Microhabitat Distribution of Dipteryx panamensis, a Neotropical Rain Forest Emergent Tree. Biotropica, v.19, n. 3, p. 236-244, 1987.

CLUTTER, J. L. et al. Timber management: a quantitative approach. New York: John Wiley, 1983, $329 \mathrm{p}$.

DURLO, M. A. RELAÇÕES MORFOMÉTRICAS PARA Cabralea canjerana (Well.) Mart. Ciência Florestal, Santa Maria, v.11, n.1, p.141-149, 2001. DURLO, M. A.; DENARDI, L. Morfometria de Cabralea canjerana, em mata secundaria nativa do Rio Grande do Sul. Ciência Florestal, Santa Maria, v. 8, n. 1, p. 55-66, 1998.

DURLO, M. A.;SUTILI, F. J.; DENARDI, L. Modelagem da copa de Cedrela fissilis Vellozo. Ciência Florestal, Santa Maria, v. 14, n. 2, p. 79-90, 2004.

FIGUEIREDO-FILHO, A. et al. Uso de cintas dendrométricas na avaliação do incremento diamétrico de algumas espécies de Floresta Ombrófila Mista. Revista Ciências Exatas e Naturais, v. 5, n. 1, Jan/Jun 2003.

GOMES, F. S. et al. Efeitos do sítio e de cenários de custos e preços na análise de regimes de manejo com e sem desbaste em Pinus taeda L. Cerne, Lavras, v. 8, n. 1, p. 13-31, 2002.

IUCN - The international union for conservation 
of nature and natural resources. Red List of Threatened Species. Disponível em $<$ www. iucnredlist.org> Acesso em: setembro 2011.

HASENAUER, H.; MONSERUD, R. A. A crown ratio model for Austrain forests. Forest Ecology and Management, v. 84, p. 49-60, 1996.

HERRERA, H. A. R. et al. Análise florística e fitossociológica do componente arbóreo da Floresta Ombrófila Mista presente na reserva florestal Embrapa/Epagri, Caçador, SC - Brasil. Floresta, Curitiba, PR, v. 39, n. 3 p. 485 - 500, jul/set 2009.

HOLMES, M. J.; REED, D. D. Competition indices for mixed species Northern Hardwoods. Forest Science, v. 37, p. 1338 1349, 1991.

HUBBELL, S. P. et al. Light-Gap Disturbances, Recruitment Limitation, and Tree Diversity in a Neotropical Forest. Science, p. 554-557, 1999.

KALIL FILHO, A. N. et al. Pré-melhoramento de populações de imbuia. Pesquisa Florestal Brasileira, Colombo, n. 57, p. 61-68, jul./dez. 2008. Nota Científica

KALIL FILHO, A. N. et al. Dinâmica da germinação de sementes de progênies de populações de imbuia (Ocotea porosa Nees et Martius ex. Nees, Lauraceae) do Paraná e de Santa Catarina. Boletim de Pesquisa Florestal, Colombo, n. 48, p. 121-128, jan./jul. 2004. Nota técnica.

KIERNAN, D. H.; BEVILACQUA, E.; NYLAND, R. D. Individual-tree diameter growth model for sugar maple trees in uneven-aged northern hardwood stands under selection system. Forest Ecology and Management. v. 256, p.1579-1586, 2008.

LISI, C. S. et al. Tree-ring formation, radial increment periodicity, and phenology of tree species from a seasonal semi-deciduous forest in southeast Brazil. Iawa Journal, v. 29, n. 2, p. 189-207, 2008. LONGHI, S. J. A estrutura de uma floresta natural de Araucaria angustifolia Bert. O. Ktze no sul do Brasil. 1980. 198 f. Dissertação (Mestrado) Universidade Federal do Paraná, Curitiba, 1980.

LORIMER, C. G., DAHIR, S. E.; SINGER, M. T. Frequency of partial and missing rings in Acer saccharum in relation to canopy position and growth rate. Plant Ecology, v. 143, p. 189 -202, 1999.

MANOKARAN, N.; K.M. KOCHUMMEN. Tree Growth in Primary Lowland and Hill Dipterocarp Forests. J.of Tropical Forest. Science, v. 6, n. 3, p. 332-345, 1993.

MATTOS, P. P. de. et al. A dendrocronologia e o manejo florestal sustentável em florestas tropicais. Colombo: Embrapa Florestas; Corumbá: Embrapa Pantanal, 2011. 37 p. (Embrapa
Florestas. Documentos, 218); (Embrapa Pantanal. Documentos, 112).

MATTOS, P. P. de. et al. Aceleração do crescimento em diâmetro de espécies da Floresta Ombrófila Mista nos últimos 90 anos. Pesquisa Florestal Brasileira, Colombo, v. 30, n. 64, p. 319-326, nov./dez. 2010.

MATTOS, P. P. de. et al. Dendrocronologia de espécies da Floresta Ombrófila Mista do Município de Candói, PR. Pesquisa Florestal Brasileira, Colombo, n. 54, p. 153-156, jan./jun. 2007. NOTA CIENTÍFICA.

MMA. Instrução Normativa n. 37. Brasília, DF: Ministério do Meio Ambiente, 1992. Disponível em: http://licenciamento.cetesb.sp.gov.br/legislacao/ federal/portarias/1992_Port_IBAMA_37.pdf. Acesso em agosto de 2011 .

MONSERUD, R. A.; STERBA, H. A basal area increment model for individual trees growing in even- and uneven-aged forest stands in Austria. Forest Ecology Management. p. 57-80, 1996.

NEGRELLE, R. A.; SILVA, F. C. Fitossociologia de um trecho de floresta com Araucaria angustifolia (Bert.) O. Ktze. no município de Caçador - SC. Embrapa Florestas. Boletim de Pesquisa Florestal, Colombo, n. 24/25, p. 37 - 54, jan/dez 1992.

NICOLINI, G. et al. Wood-growth zones in Acacia seyal Delile in the Keita Valley, Niger: Is there any climatic signal. Journal of Arid Environment, v.74, p. 355-359, 2010.

NUTTO, L. Manejo do crescimento diamétrico de Araucaria angustifolia (Bert.) O. Ktze. baseado na árvore individual. Ciência Florestal, Santa Maria, v. 11, n. 2, p. 9-25, 2001.

NUTTO, L. et al. Utilização dos parâmetros da copa para avaliar o espaço vital em povoamentos de Pinus elliottii Engelm. Boletim de Pesquisa Florestal, Colombo, n. 42, p. 123-138, 2001.

POUSSART, P. F., EVANS, M. N., SCHRAG, D. P. Resolving seasonality in tropical trees: multidecade, high-resolution oxygen and carbon isotope records from Indonesia and Thailand. Earth Planet Sci Lett, v. 218, p. 301-316, 2004.

QUICKE, H. E.; MELDAHL, R. S.; KUSH, J. $\mathrm{S}$. Basal area growth of individual trees: a model derived from a regional longleaf pine growth study. Forest Science, v. 40, p. 528-42, 1994.

RICKEN, P. et al. Crescimento diamétrico de povoamento de Toona ciliata var. australis em Adrianópolis, PR. Colombo: Embrapa Florestas, 2011. 4 p. (Embrapa Florestas. Comunicado técnico, 285). 
RODRIGUEZ, L. C. E. Gerenciamento da produção florestal. Escola Superior de Agricultura "Luiz de Queiroz" Universidade de São Paulo. Documentos florestais. Piracicaba, v. 13, p. 1-41, Mai.1991. ROMAN, M.; BRESSAN, D. A.; DURLO, M. A. Variáveis morfométricas e relações interdimensionais para Cordia trichotoma (Vell.) Arráb. ex Steud. Ciência Florestal, Santa Maria, v. 19, n. 4, p. 473-480, jul./set. 2009. Nota Técnica. RONDON NETO, R. M. Análise do Histórico Silvicultural de Quatro Espécies de uma Floresta Ombrófila Mista com Auxílio da Dendrocronologia. 2003. 124 p. (Tese Doutorado) - Universidade Federal do Paraná, Curitiba, 2003.

ROSAS, M. P. Alternativas de determinação da idade técnica de corte de Eucalyptus urophylla., 1994. 85 p. Dissertação (Mestrado) - Universidade Federal de Viçosa, Viçosa, 1994.

SANQUETTA, C. R. et al. Dinâmica de um remanescente de Floresta Ombrófila Mista no sul do Paraná sob influência de taquaras. Ambiência Revista do Setor de Ciências Agrárias e Ambientais, v. 3, n. 1, jan./abr., 2007.

SANTOS, A. T. dos. et al. Equação de volume e relação hipsométrica para plantio de Ocotea porosa. Pesquisa Florestal Brasileira, Colombo, v. 32, n. 69, p. 13-21, jan./mar. 2012.

SANTOS, K. et al. Equações Volumétricas por Classe Diamérica para Algumas Espécies Folhosas da Floresta Ombrófila Mista no Paraná, Brasil. Revista Ciências Exatas e Naturais, v. 8, n. 1, jan/ jun 2006.

SCHAFF, L. B. et al. Modificações florístico - estruturais de um remanescente de Floresta Ombrófila Mista montana no período entre 1979 e 2000. Ciência Florestal, Santa Maria, v.16, n. 3, p.271 - 291, 2006.

SCHAAF, L. B. et al. Incremento diamétrico e em área basal no período 1979-2000 de espécies arbóreas de uma floresta ombrófila mista localizada no sul do Paraná. Floresta, Curitiba, v. 35, n. 2, p.
271-290, 2005.

SCHNEIDER, P. R.; SCHNEIDER, P. S. P. Introdução ao Manejo Florestal. Santa Maria: FACOS - UFSM. 2008. 566 p.

SILVA, R. P. et al. Uso de banda dendrométrica na definição de padrões de crescimento individual em diâmetro de árvores da Bacia do Rio Cuieiras. Acta Amazonica. v. 33, n. 1, p. 67-84, 2003.

SPIECKER, H. Tree rings and forest management in Europe. Dendrochronologia, v. 20, n. 1-2, p. 191-202, 2002.

STERBA, H.; BLAB, A.; KATZENSTEINER, $\mathrm{K}$. Adapting an individual tree growth model for Norway spruce (Picea abies L. Karst.) in pure and mixed species stands. Forest Ecology and Management, v. 159, p. 101-110, 2002.

STOCKS, J. J. Dinâmica de copa, crescimento e viabilidade econômica de um povoamento de Eucalipto submetido a desrama e desbaste. 2007. 89 p. Dissertação (Mestrado) - Universidade Federal de Viçosa, 2007.

TOMAZELLO FILHO, M. et al. Anatomical features of increment zones in different tree species in the State of São Paulo, Brazil. Scientia Forestalis, Piracicaba, n. 66, p. 46-55, dez. 2004.

TONINI, H.; ARCO-VERDE, M. Morfologia da copa para avaliar o espaço vital de quatro espécies nativas da Amazônia. Pesquisa Agropecuária Brasileira., Brasília, v. 40, n. 7, p. 633-638, jul. 2005.

VANCLAY, J. K. Modelling forest growth and yield: applications to mixed tropical forests Wallingford: CAB International, 1994. $312 \mathrm{p}$.

WYKOFF, W. R. A basal area increment model for individual conifers in the Northern Rocky Mountains. Forest Science, v. 36, p. 1077-1104, 1990.

ZAMPIERI, L.; SALVADOR, E. D. Levantamento de três espécies arbóreas nativas produtoras de madeiras nobres no município de Turvo - PR. Revista Eletrônica Lato Sensu, n. 1, p. 32 - 43, dez. 2006. 